\title{
O Direito Autoral e o Uso de Ferramentas de Inteligência Artificial - Aspectos Jurídicos e Tecnológicos
}

\section{Copyright Law and the Use of Artificial Intelligence Tools - Legal and Technological Aspects}

\author{
Carla Frade de Paula Castro ${ }^{1}$ \\ Jonath de Andrade Oliveira ${ }^{2}$ \\ Lucas Barbosa de Araújo ${ }^{3}$ \\ Luciano Andrade Pinheiro ${ }^{1}$ \\ ${ }^{1}$ Universidade de Brasília, Brasília, DF, Brasil \\ ${ }^{2}$ Ministério da Ciência, Tecnologia, Inovações e Comunicações, Brasília, DF, Brasil \\ ${ }^{3}$ Corrêa da Veiga Advogados, Brasília, DF, Brasil
}

\begin{abstract}
Resumo
O termo "Inteligência Artificial" (IA) até pouco tempo tratava-se apenas de algo utópico, digno de ficção científica, mas, hoje, até mesmo de forma não visível à maioria das pessoas, está presente no nosso cotidiano das mais diversas formas. No âmbito das artes, essa expressão já é responsável por gerar músicas, pinturas e textos com cada vez menos interferência humana. Dado o potencial financeiro de tais obras e a importância de se incentivar sua criação, este trabalho tem por objetivo trazer uma breve reflexão sobre a viabilidade de sua proteção pelo Direito Autoral brasileiro. Partindo dos conceitos de obra e de titularidade, originária e derivada, conclui-se que, atualmente, essa proteção não existe no país. Nesse sentido, uma eventual proteção que se queira outorgar a tais obras deverá ser feita mediante alteração legislativa.
\end{abstract}

Palavras-chave: Propriedade Intelectual. Direito Autoral. Inteligência Artificial.

\begin{abstract}
The term "Artificial Intelligence" was, until recently, something utopian, worthy of science fiction. Today, it is present in our daily lives in many different ways, even if most of us don't notice it. In the arts domain, it is already responsible for generating music, paintings and texts with less and less human interference. Given the financial potential of such works and the importance of encouraging their creation, this work aims to bring a brief reflection on the feasibility of their protection under Brazilian Copyright Law. Based on the concepts of work and of ownership, original and derived, we conclude that, currently, such protection does not exist in Brazil. In this sense, any protection that may be granted to such works must be made through a legislative amendment.
\end{abstract}

Keywords: Intellectual Property. Copyright. Artificial Intelligence.

Área Tecnológica: Propriedade Intelectual. Sistemas de Informação. 


\section{Introdução}

As aplicações de tecnologias de Inteligência Artificial (IA), entre as quais se situa o desenvolvimento de produtos de caráter artístico ${ }^{1}$, representam atualmente ativos relevantes dos pontos de vista tecnológico, econômico e, enfim, jurídico. $\mathrm{O}$ fato de se tratar de fruto de um sistema de inteligência artificial, por exemplo, não obstou a que um retrato denominado Edmond de Belamy, produzido sob a iniciativa de um coletivo de artes, fosse leiloado em outubro de 2018 pela prestigiosa Christie's; e, tampouco, impediu que tal obra fosse arrematada por impressionantes US\$ 432 mil (CHRISTIE'S, 2018).

Ao se aperfeiçoar aquele negócio jurídico, no caso, a venda de uma pintura, pairam, sem resposta, questionamentos pertinentes no tocante à definição de instrumentos normativos adequados a subsidiar a exploração econômica de produtos desenvolvidos por ferramentas de IA, notadamente quando são reivindicados status estético, artístico ou científico. $\mathrm{O}$ direito de autor pode ser uma importante ferramenta, nesse sentido, por conferir ao titular de obras intelectuais prerrogativas exclusivas de utilização, fruição, disposição, entre outras, na forma do artigo 28 da Lei n. 9.610/1998 - Lei de Direitos Autorais (BRASIL, 1998b).

Cabe, naturalmente, ao titular de direitos autorais a faculdade de ofertar autorização, gratuita ou onerosa, temporária ou definitiva, que transmita, ao usuário interessado, direitos patrimoniais de utilização de suas obras intelectuais, tais quais reprodução, edição, adaptação, tradução, distribuição. O autor congrega, ainda, importantes direitos morais, como o de reivindicar a autoria da obra, o de ter seu nome indicado como autor e o de conservar a obra inédita, nos termos do artigo 24 da legislação autoral. Todavia, é possível identificar, como verdadeiras obras intelectuais, os produtos desenvolvidos por ferramentas de IA? Além disso, a qual sujeito deve pertencer a titularidade originária de direitos autorais eventualmente incidentes sobre esses produtos?

Partindo dessas indagações, este trabalho tem como objetivo precípuo identificar quais as soluções que têm sido debatidas pela doutrina com relação à incidência de normas de direitos autorais sobre produtos decorrentes de máquinas e/ou sistemas que contêm funções de IA. Para tanto, será inicialmente apresentada a metodologia de pesquisa utilizada; a fim de justificar, em seguida, a elaboração de breve apanhado teórico em que serão delimitados e abordados os conceitos de IA, bem como os principais - e clássicos - institutos do direitos autoral que têm sido desafiados pela deflagração e consolidação desta nova tecnologia, a saber, os conceitos de obra e de titularidade. Na sequência, serão apresentadas as opções identificadas pela doutrina com vistas ao tratamento legislativo do tema, inclusive com amparo na experiência de outros países.

Espera-se contribuir para uma melhor reflexão sobre o assunto, o qual ganha especial importância em vista do atual contexto de revisão da Lei de Direitos Autorais, promulgada no final da década de noventa, sem que se tenha considerado normativamente o advento, então contemporâneo, da internet e dos mecanismos de digitalização, ora difundidos e estabilizados socialmente.

\footnotetext{
${ }^{1}$ É possível identificar ainda outros exemplos de inteligência artificial que produzem música (Watson Beat, Jukedeck e WaveNet), imagens (DeepDream) e textos (Automated Insights e Narratives Science). O sistema Watson Beat é capaz de compor novas músicas a partir de interpretações de apenas vinte segundos de outras obras musicais, enquanto o DeepDream cria imagens originais independentemente de qualquer direção humana, a partir da detecção de ruídos visuais em outras figuras. Finalmente, Automated Insights e Narrative Science são utilizados por plataformas de comunicação conhecidas, como The Associated Press e Forbes, para produção de relatórios textuais acerca de eventos reais (PALACE, 2018, p. 223).
} 


\section{Metodologia}

A presente pesquisa tem objetivo marcadamente exploratório, considerada a novidade do tema e a escassa existência de normas positivadas que lhe sejam correspondentes (GERHARDT, 2009). Sendo assim, pretende-se tornar mais explícitos e acessíveis, à luz da legislação brasileira vigente, que serve de marco teórico, os conceitos jurídicos e tecnológicos que sedimentam a discussão em derredor da possível incidência de normas de direitos autorais sobre produtos de IA.

A metodologia adotada neste trabalho consiste, portanto, no levantamento e na revisão bibliográficos de estudos doutrinários que versem sobre as temáticas de Direito Autoral, de IA, bem como acerca de sua específica correlação, que consubstancia o mote central da pesquisa. Além disso, a fim de construir hipóteses teóricas de pertinente inovação legislativa, apresentam-se exemplos de como outros países têm endereçado problemáticas semelhantes, a fim de subsidiar o aprimoramento do direito nacional a partir do estabelecimento de uma relação funcional entre as normas comparadas e o problema social que orienta a análise comparativa (MICHAELS, 2006).

A partir da busca textual acerca dos eixos de abordagem a serem discutidos no trabalho e da assimilação estruturada de fatos, conceitos e abordagens normativas relacionados à averiguação da repercussão de normas de direitos autorais sobre produtos desenvolvidos por IA, operou-se a construção metodológica deste artigo. Ao cabo, esses elementos de pesquisa fomentam a indicação dos possíveis cenários de alteração legislativa sobre o tema.

A busca dos referenciais teóricos foi realizada nos portais Google Scholar, SciELO, Eric, SSRN, Hein Online e o Portal da Capes. Foram utilizados os seguintes componentes-chave para a pesquisa: Inteligência Artificial, Direito Autoral, Propriedade Intelectual e seus equivalentes em inglês. Os resultados obtidos foram analisados em vista de sua relevância para embasar este trabalho, tendo-se optado por utilizar aqueles indicados nas referências bibliográficas ao final do texto.

\section{Resultados e Discussão}

A análise da compatibilidade entre a tutela ofertada pelas normas de direitos autorais, de um lado, e os produtos de IA, de outro, pressupõe logicamente a compreensão dos aspectos conceituais do que vem a ser Inteligência Artificial e do que se entende classicamente como Direito Autoral - seu objeto de proteção e as possibilidades de titularidade correspondentes.

Esta análise teórica desempenha influência decisiva, positiva ou negativamente, na subsunção das normas de direitos autorais vigentes sobre sistemas de IA. Em outras palavras, somente após a definição dos conceitos de Inteligência Artificial, do Objeto do Direito Autoral e da Titularidade em Direito Autoral é que se poderá compreender se os produtos de ferramentas de IA consubstanciam obras intelectuais suscetíveis de proteção pelo Direito Autoral, bem como se a estes sistemas ou a outros sujeitos de direitos se pode atribuir espécie de titularidade originária ou derivada de direitos autorais. 


\subsection{Conceito de Inteligência Artificial}

Em primeiro lugar, cumpre entender o conceito de Inteligência Artificial. Em seu estudo sobre o tema, Gonçalves (2019, p. 32-33) identificou que o termo comporta uma multiplicidade de definições, como as descritas a seguir:

Segundo McCarthy (1955), trata-se da "teoria e o desenvolvimento de sistemas de computador capazes de realizar tarefas que normalmente requereriam inteligência humana, como percepção visual, reconhecimento de fala, tomada de decisões e tradução entre línguas".

Outra definição, de Russell e Norvig (2016), traz Inteligência Artificial como sendo "o estudo e concepção de agentes inteligentes, onde um agente inteligente é um sistema que percebe seu ambiente e realiza ações que maximizam suas chances de sucesso". Na mesma linha, Kurzweil (1990) trata IA como sendo "A arte de criar máquinas que desempenhem funções que requeiram inteligência quando realizadas por pessoas".

Independentemente da definição adotada, o fato é que as aplicações de IA se encontram amplamente difundidas nos dias de hoje. A partir da análise de dados em grande escala, identificam-se padrões/tendências e formulam-se predições de maneira automática, com velocidade e precisão (SALESFORCE, 2017). Assim, estes sistemas possuem um grande papel na síntese e automação de tarefas intelectuais (CANTALI, 2018, p. 10).

Dentro dessa grande área do conhecimento, a subárea do machine learning - aprendizado da máquina, tem adquirido especial importância, e constitui a base dos produtos artísticos em discussão. Em síntese, ela trata de desenvolver sistemas capazes de aprender a partir de dados (SCHÜSSLER; BASTIANI; BUSSLER, 2018, p. 2). Como explica Salesforce (2018), esse aprendizado decorre de processamentos amparados na elaboração de algoritmos ${ }^{2}$ que, ao organizar dados e reconhecer padrões, fazem com que computadores possam aprender com esses modelos a executar tarefas de forma autônoma, sem necessidade de programação prévia: diante da exposição a novos dados, os algoritmos "[...] se adaptam a partir dos cálculos anteriores $e$ os padrões se moldam para oferecer respostas confiáveis".

O deep learning (aprendizagem profunda), por sua vez, é uma técnica de machine learning que busca processar os dados da mesma maneira como é feito pela rede neural humana. Nessa técnica, os dados são submetidos a várias camadas de processamento, cada uma com um algoritmo simples e uniforme responsável por realizar um tipo de função. Alguns exemplos de suas aplicações práticas incluem o reconhecimento de imagens e de fala, o processamento da linguagem natural e o aprendizado de tarefas extremamente avançadas sem interferência humana (SALESFORCE, 2018).

No que diz respeito à criação artística, é importante distinguir entre quatro usos possíveis da IA, conforme explicados por Bøhler (2017, p. 17-18). No primeiro, a utilização de IA possui caráter meramente instrumental, voltado à implementação do processo criativo de seu operador humano. Já o segundo se refere a obras geradas por IA, mas selecionadas por humanos, que

\footnotetext{
${ }^{2}$ Um algoritmo é um conjunto de fórmulas, regras e parâmetros computáveis que possibilitam a produção de um conjunto específico de informações (output) quando na presença de um conjunto específico de informações (input) (KNUTH apud ZILIO, 2009, p. 210). Em outras palavras, consistem numa sequência lógica, definida e finita de instruções para a execução de uma determinada tarefa. (SALESFORCE, 2018)
} 
utilizam de seu discernimento para distinguir obras entre esteticamente adequadas e inadequadas. O terceiro uso, denominado "força bruta", refere-se à produção de trabalhos a partir da maior combinação possível de variáveis, sem que o programador determine orientações no projeto.

Por fim, existem os produtos de IA que foram inteiramente gerados com quase nenhuma interferência humana: os programadores são responsáveis por criar o algoritmo, definindo os parâmetros que vão guiar o processo criativo, alimentando-o com dados que constituirão a base de seu aprendizado - no caso da tela leiloada, foram 15 mil retratos pintados entre os séculos XIV e XX (CHRISTIE'S, 2018). A partir disso, as redes neurais do programa desenvolvem uma série de obras e, então, selecionam aquelas que correspondem aos parâmetros definidos pelo programador (GUADAMUZ, 2017). O homem, apesar de "[...] autor do código original, não tem controle sobre as ações e as produções da inteligência artificial” (FENALAW, 2019).

É a esta última categoria de produtos que o trabalho se dedica. Afinal, é justamente o fato de uma IA prescindir de contribuição humana para conceber e desenvolver, autonomamente, produtos que virtualmente contemplem expressões de natureza estética, artística ou científica que inaugura dúvida razoável quanto à sua equiparação às obras intelectuais tuteladas pelo Direito Autoral. É, portanto, necessário compreender como se consolidaram normativamente os conceitos clássicos que situam o Objeto do Direito Autoral, além daqueles que delimitam os contornos da atribuição de Titularidade em Direito Autoral.

\subsection{Objeto do Direito Autoral}

A delimitação do Objeto do Direito Autoral auxilia na compreensão dos requisitos normativos exigidos pela legislação com vistas à definição dos produtos que podem ser abrangidos pelo conceito de obra intelectual. É importante mencionar, preliminarmente, que objeto do Direito Autoral pode ter duas conotações. A primeira é o campo de estudo, ou seja, o escopo da proteção, do direito, enfim, tudo aquilo sobre em que deve o autoralista se debruçar para compreender e explicar a ciência em matéria autoral. A segunda refere-se a quais obras ou quais criações intelectuais são efetivamente protegidas pelo direito do autor.

Com relação àquela primeira acepção, Chaves (2008, p. 28) afirma que o Direito Autoral pode ser entendido como:

O conjunto de prerrogativas que a lei reconhece a todo criador intelectual sobre suas produções literárias, artísticas ou científicas, de alguma originalidade: de ordem extrapecuniária, em princípio, sem limitação de tempo; e de ordem patrimonial, ao autor, durante toda a sua vida, com o acréscimo, para os sucessores indicados na lei, do prazo por ela fixado. Distinguem-se nele, duas esferas de atribuições: de um lado, as que pertencem ao denominado direito moral, que consiste no direito ao reconhecimento à paternidade da obras, no direito de inédito, no direito à integridade da sua criação, no de modificar a obra, de acabá-la, de opor-se a que outrem a modifique, etc.; de outro, as de natureza patrimonial, que se cifram na prerrogativa exclusiva de retirar da sua produção todos os benefícios que ela possa proporcionar, principalmente pela publicação, reprodução, representação, execução, tradução, recitação, adaptação, arranjos, dramatização, adaptação ao cinema, à radiodifusão, à televisão, etc. 
Para a segunda acepção, o artigo 703, da Lei de Direitos Autorais (BRASIL, 1998b), traz os requisitos para que uma obra possa ser protegida pelo Direito Autoral. A opção do legislador brasileiro por enumerar, nos incisos daquele artigo, quais obras podem ser protegidas não implica, contudo, proteção automática para aquelas obras listadas. Para que isso seja possível, a doutrina aponta a necessidade de conjugação dos requisitos de exteriorização, fixação, originalidade e criatividade.

O primeiro dos elementos para a configuração de uma obra protegida é a exteriorização. É, de fato, a exteriorização formal de um pensamento que revela para o mundo a obra intelectual $^{4}$. Enquanto houver apenas ideias não haverá efetiva criação e, portanto, proteção autoral. A fixação, por sua vez, pode se dar nos mais diversos meios - tangíveis ou intangíveis, desde que seja um formato perceptível aos sentidos humanos ${ }^{5}$.

Não basta que o pensamento seja exteriorizado e fixado para que receba proteção do Direito Autoral. É necessário também que ele seja minimamente ${ }^{6}$ original. A originalidade, contudo, não é sinônimo de novidade. Originalidade implica saber se a obra nascida tem traços característicos próprios que traduzem a visão de mundo do autor e, assim, a diferenciam de outra pré-existente (LANGE, 1996, p. 21). Conforme explica Costa Netto (1998, p. 57), a originalidade deve ser entendida:

[...] de maneira subjetiva, tendo em vista as características próprias à modalidade da obra intelectual em questão. Já a novidade, requisito, principalmente, para obtenção de privilégios no campo da propriedade industrial, onde um modelo, desenho ou invenção tem que, necessariamente, trazer uma característica inovadora, é uma concepção de natureza objetiva. ${ }^{7}$

A criatividade é o último requisito e, sem dúvida, o maior causador de divergência entre as opiniões acerca da proteção de determinada criação. Ela se revela no ato de criador e, como já afirmado, se traduz no detalhe que o autor acrescenta à realidade. Não cabe à criatividade análise de mérito ou de valor acerca da obra: a obra criativa terá a mesma relevância para o Direito Autoral se produzida por um autor conhecido ou por um ilustre desconhecido.

Ascensão (1997, p. 51) explica que "[...] quando é o objeto que comanda em vez de o papel predominante ser o da visão do autor - saímos do âmbito da tutela [...]", arrematando mais adiante: "[...] por isso, dissemos já também que, se alguém deixar uma câmara de filmar aberta sobre o público, o filme daí resultante não é uma obra, é a tradução servil da realidade, sem haver marca pessoal na sua captação". Da mesma forma, Hammes (2002, p. 51) afirma que "[...] não é protegível o efeito de um trabalho físico [...]", sem um esforço intelectual que faça nascer uma criação digna de proteção. A mera repetição, a simples descrição, não gera proteção.

Em vista desses requisitos, entende-se, enfim, que a obra produzida por IA pode satisfazer, em tese, aos requisitos de exteriorização, fixação, originalidade. No que diz respeito a este último

\footnotetext{
3 "Art. $7^{\circ}$ São obras intelectuais protegidas as criações do espírito, expressas por qualquer meio ou fixadas em qualquer suporte, tangível ou intangível, conhecido ou que se invente no futuro, tais como: [...]." (BRASIL, 1998b)

${ }^{4}$ Ver, a esse respeito, o artigo $8^{\circ}$, inciso I, da Lei n. 9.610/98.

${ }^{5}$ Lipszyc (2001, p. 63) afirma enfática: "Solo está protegida la forma sensible bajo la cual se manifiesta la idea y no la idea misma, ya sea que se encuentre expresada de manera esquemática o bien en una obra. El derecho de autor protege la expresión formal del desarrollo del pensamiento, otorgando al creador derechos exclusivos de carácter patrimonial a la publicación, difusión y reproducción de la obra y derechos de carácter personal".

${ }^{6}$ Uma criação pode conter mais ou menos originalidade de acordo com a capacidade criativa do autor, mas esta mesma obra não receberá maior ou menor proteção se tiver mais ou menos originalidade. Para haver proteção autoral plena bastará que não seja cópia fiel ou disfarçada de outra pré-existente. O trabalho que tiver um mínimo de originalidade receberá, sem restrições, todas as faculdades inerentes à autoria.

${ }^{7}$ No mesmo sentido, ver Lipszyc (2001, p. 65).
} 
requisito, destaca-se a título de esclarecimento que, em razão da utilização dos mencionados sistemas de machine learning e deep learning, acima abordados, é reconhecidamente possível que ferramentas de IA produzam resultados surpreendentes e inesperados (GONÇALVES, 2019, p. 106). Apesar de seus algoritmos consistirem numa complexa lista formal de instruções executadas em ordem certa, o produto decorrente destes processos não pode ser conhecido a menos que o programa seja derradeiramente executado.

Entretanto, por se tratar de execução de um programa metodologicamente organizado por meio de sistemas algorítmicos, não pode ser enquadrada como obra intelectual protegida pelo Direito Autoral, por faltar-lhe, justamente, a dimensão da criatividade, subentendida como a expressão de um esforço criador mínimo e, como se verá adiante, especificamente de caráter humano. Cabe avaliar, finalmente, qual o sujeito a que o ordenamento jurídico brasileiro atribui a titularidade de obras intelectuais e se uma IA pode enquadrar-se aos requisitos normativos pertinentes à definição de autoria.

\subsection{Titularidade em Direito Autoral}

A titularidade em Direito Autoral é um dos temas mais controvertidos em razão, principalmente, da profunda alteração sofrida na disciplina da matéria pela legislação atual em comparação com a legislação anterior (BRASIL, 1973). Seguindo a tendência dos países de origem latina, a atual Lei de Direitos Autorais (BRASIL, 1998b) consagrou, em seu artigo 11, a titularidade originária para a pessoa física criadora da obra literária, artística ou científica. Entende-se, assim, que a pessoa física é a única capaz de criar e, portanto, de ser titular originária de Direito Autoral - em outras palavras, de ser autora.

Nas palavras de Chaves (1995, p. 199) "[...] a qualidade de autor pertence às pessoas físicas, visto serem as que têm faculdades de criar, avaliar e sentir. Seria contrário à própria natureza das coisas atribuir a qualidade de autor de uma obra intelectual a uma pessoa jurídica" ${ }^{\text {. Pensar }}$ é ato humano, de pessoa com existência visível. Autor então é aquele que pensa e expressa seu pensamento para o mundo de qualquer forma. Acrescenta Leite (2004, p. 54) que "[...] autor é aquela pessoa que expressa suas ideias, fazendo com que estas saiam do campo mental, sejam exteriorizadas e desenvolvendo um conteúdo acerca de um determinado assunto ou tema".

A pessoa jurídica, por sua vez, é titular de direitos e age por meio de uma ficção jurídica, o que a princípio não é compatível com o direito de autor. Quanto ao Direito Autoral, aquele mesmo artigo 11 (BRASIL, 1998b), em seu parágrafo único, possibilitou-lhes a titularidade originária em casos excepcionais, como nas hipóteses do editor, do produtor e do organizador da obra coletiva.

É preciso então estabelecer que a autoria ${ }^{9}$ é exclusiva da pessoa física e em regra se confunde com a titularidade originária ${ }^{10}$. A titularidade derivada, por sua vez, consiste no exercício de alguns direitos originalmente atribuídos ao criador, mas transmitidos às pessoas físicas ou jurídicas por meio de negócios inter vivos ou mortis causa. ${ }^{11}$

\footnotetext{
${ }^{8}$ No mesmo sentido, Lipszyc (2001, p. 123): "Las personas físicas son las únicas que tienen aptitud para realizar actos de creación intelectual. Aprender, pensar, sentir, componer y expresar obras literarias, musicales y artísticas, constituyem acciones que solo pueden ser realizadas por seres humanos".

9 "Autoria de uma obra intelectual é o ato voluntário que dá uma forma específica a uma idéia para desenvolver-lhe o conteúdo, de acordo com sua modalidade de expressão". (MANSO, 1992, p. 58-59)

10 "Quem seja o titular originário do direito de autor facilmente se compreende: aquele que idealiza, concebe, realiza e faz vir a lume uma obra intelectual." (CHAVES, 1995, p. 83).

11 "Originalmente, pois, o título jurídico que sustenta o Direito em causa é a criação, mas, pode ocorrer, ainda, a assunção, por terceiros, de certos direitos, por vias derivadas, a saber, por lei (vínculo sucessório), ou por vontade do autor (vínculo contratual). Por princípio, pois, o suporte fático do Direito é a criação". (BITTAR, 1977, p. 32-33).
} 


\subsection{Autoria e Titularidade de Produtos Gerados por Sistemas de Inteligência Artificial}

Como se depreende do marco teórico acima consolidado, ainda que se imagine a possibilidade de que um sistema de IA tenha a capacidade de produzir obras intelectuais no sentido normativo deste conceito, tal fato ainda não seria suficiente para que este produto receba a tutela do Direito Autoral. Afinal, a Lei de Direitos Autorais (BRASIL, 1998b) estipula expressamente em seu artigo 11 que apenas se considerará "autor" a pessoa física criadora de obra literária, artística ou científica, relegando à excepcional previsão legislativa a possibilidade de atribuição de titularidade por pessoas jurídicas.

É preciso então estabelecer que o conceito normativo de autoria abarca uma dimensão de voluntariedade, ou seja, supõe o exercício de ato voluntário que forneça forma específica a uma ideia para, em seguida, desenvolver o seu conteúdo (MANSO, 1992, p. 58-59). Como o conceito de titularidade originária, em regra, confunde-se com a própria autoria, o direito que exsurge da criação terá como titular exclusivo a pessoa que desenvolve o ato de criador.

Assim, percebe-se que o arcabouço normativo brasileiro inviabiliza a que uma IA, por não se tratar de pessoa física ou jurídica, adquira qualquer sorte de prerrogativas legais sobre produtos que conceber autonomamente, ainda que fossem considerados compatíveis com o conceito de "obra intelectual", tal como definido no artigo $7^{\circ}$ da Lei de Direitos Autorais (BRASIL, 1998b).

O pressuposto normativo de que haja um autor humano subjetivamente responsável pela criação de uma obra intelectual é reproduzido por diversos sistemas jurídicos, vigentes em países como EUA, Canadá, Austrália (GINSBURG apud SOUZA; JACOSKI, 2018, p. 3), e na maioria dos países europeus, incluindo Espanha, Alemanha, França, Bélgica, Holanda e Reino Unido (GUADAMUZ, 2017; SOUZA; JACOSKI, 2018, p. 3).

Especificamente nos Estados Unidos, o U.S. Copyright Office ${ }^{12}$ (2017) estatuiu que o conceito de autoria (authorship) é apenas concebível como um desdobramento da atividade criativa humana, o que significa não serem passíveis de registro, como obras intelectuais, as criações de máquinas ou sistemas computadorizados. Embora essa visão tenha sido adotada (e reproduzida) pelo judiciário estadunidense ${ }^{13}$, alguns autores argumentam que o requisito de autoria humana seria anacrônico e ambíguo. Essa posição se sustenta, de um lado, em precedentes judiciais da Suprema Corte dos Estados Unidos pronunciados há mais de cem anos ${ }^{14}$ e, de outro, por não anteverem a capacidade de um sistema computadorizado conceber obras efetivamente dotadas de originalidade, sem qualquer contribuição humana ${ }^{15}$.

Da mesma forma, o Tribunal de Justiça da União Europeia acumula decisões que afirmam que apenas obras originais podem ser objeto de proteção autoral, e que uma tal originalidade

\footnotetext{
${ }^{12}$ O U.S. Copyright Office é o departamento federal que presta consultoria ao Congresso estadunidense em matéria de direito autoral e administra a aplicação de diplomas como o Copyright Act (1976) e o Digital Millennium Copyright Act (1998).

${ }^{13}$ Há precedentes em que o judiciário estadunidense se debruça sobre a possibilidade de reconhecer a autoria de animais sobre obras intelectuais. Por exemplo, o caso Naruto $v$. Slater, em que um macaco utilizou-se do equipamento de um fotógrafo para tirar uma sequência de selfies (EUA, 2016).

${ }^{14}$ Em um destes julgados paradigmas (Burrow-Giles Lithographic Co. v. Sarony), cumpre destacar, a Suprema Corte dos EUA reconhecia a possibilidade de tutelar direitos exclusivos sobre fotografias, apesar de o Copyright Act referir-se apenas à proteção de manuscritos (writings). Nessa oportunidade, a Corte endossou que o fator essencial para que vindicada a proteção a título de direitos autorais (copyright) era a originalidade, sem destacar qualquer critério especificamente relativo ao autor, registrando que o dispositivo normativo aplicável apenas deixara de mencionar fotografias porque ainda não tinham sido inventadas à data de sua promulgação. A despeito da interpretação erigida pelo Copyright Office, isto sugere que uma obra intelectual, assim considerada, é passível de proteção pelo direito autoral independentemente de quem for o seu criador (PALACE, 2018, p. 230).

${ }^{15}$ Apesar de o Copyright Office consignar, em tradução livre, que "não registrará obras desenvolvidas por máquinas [...] que operam aleatória ou automaticamente sem que haja intervenção criativa de um autor humano", os exemplos que apresenta para delimitar o significado das obras não protegidas (por exemplo, a mera transposição da tonalidade de uma música preexistente por uma máquina) é verdadeiramente incompatível com a extensão, em termos de originalidade, das criações desenvolvidas por sistemas de inteligência artificial. Ver Palace (2018).
} 
deve refletir "a própria criação intelectual do autor". Normalmente, a expressão é interpretada de modo a conceber que uma obra original deve refletir a personalidade do autor, o que supõe um autor necessariamente humano (GUADAMUZ, 2017).

Para tais jurisdições, a obra produzida por uma IA encontra-se, necessariamente, fora do escopo do Direito Autoral. Nesse caso, a ausência de tutela normativa dá ensejo a insegurança jurídica, porque, do ponto de vista do usuário, não se saberá ao certo se a obra integrará domínio público, situando-se à livre disposição de toda a coletividade. Já do ponto de vista de possíveis titulares de direitos autorais, a incerteza quanto à possibilidade de sua exploração econômica desbordará em verdadeiro desincentivo ao desenvolvimento e ao aprimoramento de tais tecnologias.

Para remediar essa situação, resta apenas a hipótese de alteração legislativa. Nesse sentido, entende-se que há duas abordagens possíveis.

\subsection{Regimes Jurídicos Possíveis para Produtos de Sistemas de Inteligência Artificial}

Caso se deseje legislar sobre o tema, a primeira opção, e por ora definitivamente a mais remota, é a de que ordenamentos jurídicos passem a conferir verdadeira personalidade jurídica à IA, e, com isso, alçar voo para além dos limites antropocentristas que historicamente circunscreveram o escopo da tutela jurídica. Esta concepção, além de inaugurar uma dimensão normativa de feição pós-humana (SORJAMAA, 2016, p. 3), carreia consigo sérias dificuldades de ordem pragmática e filosófica.

Admitida essa profunda alteração legislativa, a titularidade de direitos autorais compreende dimensão reduzida da discussão, a qual engloba um amplo universo de legitimidades albergadas por IA, que deve variar segundo o seu grau de autonomia, a fim de que possam, inclusive, ser civilmente responsabilizados por danos a que derem causa (SOUZA; JACOSKI, 2018, p. 8).

Essa opção impõe uma séria reflexão sobre vários aspectos de Direito Autoral. A duração dos direitos autorais titularizados por IA é um deles, porque deverá ser distinta daquela prevista atualmente na legislação. Como visto, a regra geral, nos termos do artigo 41 da Lei de Direito Autoral (BRASIL, 1998b), é que direitos patrimoniais sobre obras intelectuais sejam exercidos pelo autor durante toda a sua vida e, ainda, setenta anos após a sua morte. A duração estipulada pelo ordenamento estadunidense é idêntica, no que concerne aos direitos autorais patrimoniais (EUA, 2006). Finalmente, a Convenção de Berna (BRASIL, 1975), que é genericamente aplicável ao redor do mundo, estipula que a proteção mínima deve alcançar os cinquenta anos póstumos à morte do autor.

Verifica-se que o parâmetro utilizado para identificar o termo final da duração de direitos autorais patrimoniais é, geralmente, a data de morte do autor. Transcorrido o período previsto e extintos os direitos autorais patrimoniais, a obra se incorporará ao domínio público, conforme artigo 45 da Lei de Direitos Autorais (BRASIL, 1998b), a fim de que possa ser fruída de forma irrestrita pela coletividade. Como IA simplesmente não morrem, exerceriam titularidade exclusiva e indefinidamente sobre as eventuais obras intelectuais que criassem, em prejuízo de toda a sociedade.

Além disso, uma das principais razões para que as prerrogativas exclusivas de direitos autorais sejam conferidas a pessoas físicas é, justamente, a de que elas fornecem incentivos artificiais 
para a criação. Outra razão, típica da matriz continental de direitos autorais, repousa na ligação imanente entre a obra intelectual e o autor que a exteriorizou. Dessa relação, desdobra-se um feixe de direitos de ordem moral, como o direito a reivindicar autoria, o direito de conservar uma obra inédita, o direito de preservar a integridade da obra, entre outros previstos no artigo 24 da Lei de Direito Autoral (BRASIL, 1998b).

É evidente que sistemas de IA não precisam de qualquer tipo de incentivo para criar, além disso, não incorporaram tecnologias capazes de albergar a típica relação de intimidade e pertencimento existente entre autores e obras intelectuais, que pessoalmente concebem.

Questiona-se, nesse sentido, como justificar a atribuição de prerrogativas exclusivas da propriedade intelectual a um sistema de IA, considerando-se que a previsão de incentivos é despicienda para estimular a sua atividade criativa e que este sistema dificilmente manifestaria uma conexão moral umbilical com os produtos criativos que conceber?

Diante dessas observações, a atribuição de titularidade de direitos autorais a uma IA não parece o regime jurídico mais adequado para tutelar as suas criações.

A segunda opção legislativa refere-se à atribuição de titularidade a um ente dotado de personalidade jurídica. No Brasil, o artigo $4^{\circ}$ da Lei n. 9.609/1998 (BRASIL, 1998a), que concede proteção autoral a programas de computador, dispõe que "[...] pertencerão exclusivamente ao empregador, contratante de serviços ou órgão público, os direitos relativos ao programa de computador, desenvolvido e elaborado durante a vigência de contrato ou de vínculo estatutário, expressamente destinado à pesquisa e desenvolvimento".

Sendo "[...] uma aplicação de Inteligência Artificial um programa de computador feito a partir de algoritmos mais ou menos complexos" (GONÇALVES, 2019, p. 67), garante-se ao empregador, que pode ser pessoa jurídica, a titularidade dos direitos autorais sobre o software desenvolvido com amparo em um contrato de trabalho especificamente pactuado para esta finalidade. Esses direitos, contudo, não abrangem ou autorizam o exercício de qualquer prerrogativa de propriedade intelectual sobre os frutos criativos do software, que pode se tratar de um sistema de IA.

Em alguns países, nada obstante, os direitos decorrentes de criações desenvolvidas por IA foram atribuídos, por ficção jurídica, a outros titulares casuisticamente designados, como o seu programador, a empresa proprietária ou o eventual usuário (GERVAIS, 2019, p. 46). É o caso de Hong Kong, Índia, Irlanda, África do Sul, Nova Zelândia e Reino Unido (SOUZA; JACOSKI, 2018, p. 3).

Com relação a este último, seu Copyright, Designs and Patents Act (CDPA) estabelece na seção 9(3) que, "[...] no caso de obra literária, dramática, musical ou artística geradas por computador, o autor deverá ser considerado a pessoa que fez os arranjos necessários para a criação da obra". Em complemento, a seção 178 do CDPA determina que "[...] são consideradas obras criadas por computadores, aquelas criadas em circunstâncias em que não há um autor humano" (OLIVEIRA, 2018).

A proposição da seção 9(3) é criticada por sua falta de clareza, uma vez que a determinação de quem é a pessoa que viabilizou a criação do produto só poderá ser feita no caso concreto. Como visto, o autor responsável pela produção de um trabalho gerado por IA pode incluir personagens tão diferentes quanto o usuário, o programador e um investidor, ou até mesmo a combinação deles, a depender do trabalho específico em questão (SOUZA; JACOSKI, 2018, p. 4). 
Qual, então, o melhor critério? Souza e Jacoski (2018, p. 4) mencionam, como exemplos, a iniciativa de criar o produto, a proximidade com o ato final de criação e a medida com que estes arranjos contribuíram para a criação do produto. Todos esses são aspectos relevantes e, no entanto, ignorados pelo legislador britânico. Além disso, a necessidade de se aferir o autor em cada caso traz alguma dificuldade para a aplicação da lei.

A aplicação por analogia do regime legal previsto para tutelar a titularidade de obras coletivas é também uma opção viável. Os direitos autorais sobre o produto da IA seriam atribuídos ao organizador do processo criativo, que pode ser tanto a pessoa física quanto a pessoa jurídica. A duração desses direitos autorais observaria a regra do post publicacionem operis, ou seja, a contagem do prazo de setenta anos para incorporação da obra ao domínio público iniciaria no ano subsequente à primeira divulgação.

Apesar disso, nenhuma destas ficções suplantaria o fato de que a atribuição de titularidade por ficção jurídica ao programador, à empresa detentora ou ao usuário inauguraria incentivos normativos excessivos e desproporcionais (PALACE, 2018, p. 236). Isso porque o usuário já se beneficia simplesmente por se utilizar livremente da IA e das criações que autonomamente desenvolver. De outro lado, a legislação já oferta direitos exclusivos aos programadores e às companhias sobre a própria IA que desenvolverem, por se tratar ela própria de uma espécie de software.

Seguindo esse raciocínio, programadores e companhias angariariam direitos autorais sobre um número ilimitado de obras intelectuais desenvolvidas no esteio da capacidade de um sistema cuja de IA cuja propriedade já lhes é legalmente assegurada. A extensão desses direitos aos frutos criativos das inteligências artificiais é problemática, além disso, o regime da obra coletiva pressupõe a autonomia do partícipe individual, que receberia remuneração em contrapartida ao fornecimento de seu esforço criativo. O sistema de IA, diferentemente, nunca receberá qualquer tipo de contraprestação.

Portanto, esse tipo de conformação normativa poderá resultar em um indesejável movimento de concentração da utilização de IA e de seus produtos criativos, em razão do potencial econômico desproporcional que o regime ofereceria ao programador ou à empresa, ou aos proprietários do software, qual seja, a titularidade sobre um número sem precedentes de obras intelectuais produzidas sem qualquer custo econômico ou criativo adicionais (PALACE, 2018, p. 237).

\section{Considerações Finais}

Se antes a tecnologia desempenhava um papel meramente ferramental na criação de obras intelectuais por humanos, a evolução científica recente convida a uma reflexão sobre o processo criativo das máquinas. Muito embora por detrás de toda forma de IA haja uma programação executada por humanos, hoje essa contribuição é bastante relativizada, sendo possível encontrar programas que desenvolvem e ultrapassam as instruções originais, desempenhando tarefas criativas razoavelmente páreas às criações de espírito concebidas e exteriorizadas por seres humanos.

Percebe-se, contudo, que o ordenamento jurídico brasileiro entabula definição de obra intelectual que dificilmente poderia subsumir e tutelar o objeto de criação de uma IA, apesar de a recente sofisticação deste tipo de tecnologia dar indícios de que considerações acerca dos 
regimes jurídicos aplicáveis sobre suas criações não são banais e tampouco se reduzem a elucubrações típicas da ficção científica ${ }^{16}$.

Tampouco a Lei de Direitos Autorais admite obras produzidas de forma autônoma, sem caráter humano. Diante desse impasse, entende-se que tais obras, por carecerem de proteção e de titular, nascem como de domínio público, em que pese parte da doutrina compreender que a positivação de uma tutela de direitos autorais atenuada apresentar-se-ia mais vantajoso, por convergir com o caráter historicamente flexível da proteção conferida aos objetos de desenvolvimento tecnológico (BUTLER, 1982). O mesmo ocorre nos EUA e em vários países europeus.

As descrições sumarizadas das abordagens legislativas vislumbradas por esta pesquisa estão representadas no Quadro 1:

Quadro 1 - Abordagens legislativas - Direito Autoral e IA

\section{INCIDÊNCIA DE DIREITOS AUTORAIS SOBRE PRODUTOS DE IA - A ORDAGENS LEGISLATIVAS POSSÍVEIS}

\begin{tabular}{|c|c|c|}
\hline \multicolumn{2}{|c|}{ TITULARIDADE (ATRIBUIÇÃO) } & \multirow[b]{2}{*}{$\begin{array}{l}\text { INTEGRAÇÃO AO } \\
\text { DOMÍNIO PÚBLICO }\end{array}$} \\
\hline $\begin{array}{l}\text { SISTEMAS DE } \\
\text { INTELIGENCIA } \\
\text { ARTIFICIAL }\end{array}$ & $\begin{array}{l}\text { ENTE DOTADO DE } \\
\text { PERSONALIDADE JURÍDICA } \\
\text { (programador, proprietário, } \\
\text { investidor, usuário) }\end{array}$ & \\
\hline $\begin{array}{c}\text { Conferência de } \\
\text { personalidade jurídica a } \\
\text { sistemas dotados de IA. } \\
\text { Modificação estrutural de } \\
\text { ordenamentos jurídicos } \\
\text { em prol da inauguração } \\
\text { de dimensão normativa } \\
\text { de feição pós-humana. } \\
\text { Incompatibilidades específicas: } \\
\text { (a) duração de direitos } \\
\text { (máquinas não são mortais); (b) } \\
\text { prescindibilidade de incentivo } \\
\text { material; e (c) direitos morais. }\end{array}$ & $\begin{array}{c}\text { Atribuição de titularidade sobre o } \\
\text { produto da IA, por ficção jurídica, a } \\
\text { sujeitos casuisticamente designados. } \\
\text { Criação de mecanismos jurídicos de } \\
\text { incentivo ao desenvolvimento de } \\
\text { novas obras intelectuais, em termos } \\
\text { quantitativos e qualitativos. } \\
\text { Incerteza jurídica: a determinação do titular } \\
\text { deve variar segundo o caso concreto e o } \\
\text { grau de participação do sujeito titular. } \\
\text { Incompatibilidades específicas: (a) } \\
\text { atribuição de benefícios excessivos; } \\
\text { (b) possível concentração de } \\
\text { propriedade sobre produtos de IA. }\end{array}$ & $\begin{array}{c}\text { Ausência de conferência } \\
\text { de prerrogativas exclusivas } \\
\text { de direitos autorais } \\
\text { sobre produtos gerados } \\
\text { por sistemas de IA. } \\
\text { Possibilidade de utilização } \\
\text { generalizada e irrestrita de } \\
\text { produtos decorrentes de IA. } \\
\text { Falta de incentivo ao } \\
\text { aprimoramento e ao } \\
\text { desenvolvimento de } \\
\text { novas tecnologias. }\end{array}$ \\
\hline
\end{tabular}

Fonte: Elaborado pelos autores deste artigo

Nesse exato sentido, entende-se que essa não é uma situação desejável. Dada a importância e o impacto que a IA tem e terá no cotidiano das sociedades contemporâneas e futuras, além da relevância econômica que suas criações podem assumir, a falta de proteção autoral é uma falta grave. Mais: implica verdadeiro desincentivo ao desenvolvimento e aprimoramento de tais tecnologias, na medida em que permite que as obras sejam livremente exploradas, sem que seja devida compensação ao titular ou que lhe seja requisitada autorização prévia (HRISTOV, 2017, p. 439).

\footnotetext{
${ }_{16}$ O Congresso estadunidense questiona, desde 1974, quem seria titular de uma criação concebida parcialmente por um humano e parcialmente por um sistema computadorizado. A tecnologia difundida à época tornou a resposta "óbvia": a titularidade de direitos exclusivos repousaria sempre sobre o humano ou usuário, porque máquinas seriam invariavelmente inertes, porquanto dependeriam necessariamente do trabalho humano. Ver EUA (1974).
} 
É importante salientar que o Brasil não é o único a enfrentar o dilema dos produtos derivados da IA. Em realidade, a pesquisa mostrou que a maioria dos ordenamentos normativos atualmente vigentes é essencialmente incompatível com a atribuição de titularidade sobre obras de Direito Autoral a não humanos, hipótese que vindicaria alteração legislativa. No geral, os países têm optado por uma de duas direções: ou excluir expressamente a proteção a obras não-humanas, ou atribuir o Direito Autoral a algum dos envolvidos no processo de "criação". ${ }^{17}$

Cabe ao Brasil decidir qual caminho deseja seguir. Essa discussão, porém, fica para outros trabalhos, aos quais se recomenda analisar os aspectos epistemológicos, filosóficos e tecnológicos do tema, além do jurídico.

\section{Referências}

ASCENSÃO, José de Oliveira. Direito Autoral. Rio de Janeiro: Renovar, 1997.

BITTAR, Carlos Alberto. Direito de Autor na obra feita sob encomenda. São Paulo: Revista dos Tribunais, 1977.

$\mathrm{B} \varnothing \mathrm{HLER}$, Helene Margrethe. EU copyright protection of works created by artificial intelligence systems. 2017. 37f. Dissertação (Mestrado em Direito) - Faculdade de Direito, University of Bergen, Bergen, 2017.

BRASIL. Decreto n. 75.699, de 6 de maio de 1975. Promulga a Convenção de Berna para a Proteção das Obras Literárias e Artísticas, de 9 de setembro de 1886, revista em Paris, a 24 de julho de 1971. Diário Oficial [da] República Federativa do Brasil. Brasília, DF, 9 mai 1975. Disponível em: http://www.planalto.gov.br/ccivil_03/decreto/1970-1979/D75699.htm. Acesso em: 10 jun. 2019.

BRASIL. Lei n. 5.988, de 14 de dezembro de 1973. Regula os direitos autorais e dá outras providências. Diário Oficial [da] República Federativa do Brasil. Brasília, DF, 18 dez. 1973. Disponível em: http://www.planalto.gov.br/ccivil_03/leis/L5988.htm. Acesso em: 29 jun. 2019.

BRASIL. Lei n. 9.609, de 19 de fevereiro de 1998. Dispõe sobre a proteção da propriedade intelectual de programa de computador, sua comercialização no País, e dá outras providências.

Diário Oficial [da] República Federativa do Brasil. Brasília, DF, 25 fev. 1998a. Disponível em: http://www.planalto.gov.br/ccivil_03/leis/19609.htm. Acesso em: 10 jun. 2019.

BRASIL. Lei n. 9.610, de 19 de fevereiro de 1998. Altera, atualiza e consolida a legislação sobre direitos autorais e dá outras providências. Diário Oficial [da] República Federativa do Brasil. Brasília, DF, 20 fev. 1998b. Disponível em: http://www.planalto.gov.br/ccivil_03/leis/19610.htm. Acesso em: 10 jun. 2019.

BUTLER, Timothy L. Can a Computer be and Author. Copyright Aspects of Artificial Intelligence, 4 Hastings Comm. \& Ent. L.J. 707, 1982.

CANTALI, Fernanda Borghetti. Inteligência Artificial e Direito de Autor: Tecnologia Disruptiva Exigindo Reconfiguração de Categorias Jurídicas. Revista de Direito, Inovação, Propriedade Intelectual e Concorrência, Porto Alegre, v. 4, n. 2, p. 1-21, jun.-dez. 2018. Disponível em: https:// www.researchgate.net/publication/330972277_INTELIGENCIA_ARTIFICIAL_E_DIREITO_DE_ AUTOR_TECNOLOGIA_DISRUPTIVA_EXIGINDO_RECONFIGURACAO_DE_CATEGORIAS_JURIDICAS. Acesso em: 10 jun. 2019.

\footnotetext{
${ }^{17}$ De maneira geral, não há discussão sobre o conceito de obra, pois as legislações estrangeiras se firmam em conceitos como originalidade e criatividade, e não "criação do espírito".
} 
CHAVES, Antonio. Criador da Obra Intelectual, Direito de Autor: natureza, importância e evolução. São Paulo: LTR, 1995.

CHRISTIE'S. Is artificial intelligence set to become art's next medium? Em 12 dez. 2018.

Disponível em: https://www.christies.com/features/A-collaboration-between-two-artists-one-humanone-a-machine-9332-1.aspx. Acesso em: 10 jun. 2019.

COSTA NETTO, José Carlos. Direito Autoral no Brasil. São Paulo: FTD, 1998.

EUA - ESTADOS UNIDOS DA AMÉRICA. National Commission on New Technological Uses of Copyrighted Works. Pub. L. Número 93-573, § 201. 88 Stat 1873. 1974.

EUA - ESTADOS UNIDOS DA AMÉRICA. Naruto v. Slater. número 15-CV-04324-WHO. 2016 WL 362231.

EUA - ESTADOS UNIDOS DA AMÉRICA. Copyright Act of 1976. 17 U.S.C. § 101. 2006.

FENALAW. Propriedade Intelectual x Inteligência Artificial: desafios para o advogado. 19 mar. 2019. Disponível em: https://digital.fenalaw.com.br/2019/03/19/propriedade-intelectual-xinteligencia-artificial-desafios-para-o-advogado/. Acesso em: 10 jun. 2019.

GERHARDT, Tatiana Engel. SILVEIRA, Denise Tolfo (org.). Métodos de Pesquisa. Porto Alegre: Editora da UFRGS, 2009.

GERVAIS, Daniel J. The Machine as an Author. Iowa Law Review, [S.l.], v. 105, 2019. Disponível em: https://ssrn.com/abstract=3359524. Acesso em: 10 jun. 2019.

GONÇALVES, Lukas Ruthes. A tutela jurídica de trabalhos criativos feitos por aplicações de inteligência artificial no Brasil. 2019. 143f. Dissertação (Mestrado em Direito) - Setor de Ciências Jurídicas, Programa de Pós-Graduação em Direito, Universidade Federal do Paraná, Curitiba, 2019.

GUADAMUZ, Andres. Artificial Intelligence and Copyright. WIPO Magazine, Genebra, v. 5, p. 1419, out. 2017. Disponível em: https://www.wipo.int/wipo_magazine/en/2017/05/article_0003.html. Acesso em: 10 jun. 2019.

HAMMES, Bruno Jorge. O direito de propriedade intelectual. 3. ed. São Leopoldo: Unisinos, 2002.

HRISTOV, Kalin. Artificial Intelligence and the Copyright Dilemma. IDEA: The IP Law Review, [S.l.], v. 57, n. 3, 2017.

LANGE, Deise Fabiana. O impacto da tecnologia digital sobre o direito de autor e conexos. São Leopoldo: Unisinos, 1996.

LEITE, Eduardo Lycurgo. Direito do autor. Brasília: Jurídica, 2004.

LIPSZYC, Delia. Derecho de autor y derechos conexos. Buenos Aires: Unesco, 2001.

MANSO, Eduardo J. Vieira. O que é Direito Autoral. 2. ed. São Paulo: Brasiliense, 1992.

MICHAELS, Ralf. The functional method of comparative law. In: ZIMMERMANN, Reinhard;

REIMANN Mathias (ed.). The Oxford handbook of comparative law. Oxford: Oxford University Press, 2006. p. 345-389.

OLIVEIRA, Jaqueline Simas de. Inteligência artificial cria novos desafios na área de direitos autorais. Revista Consultor Jurídico, [S.l.], 22 fev. 2018. Disponível em: https://www.conjur.com.br/2018fev-22/jaqueline-simas-inteligencia-artificial-desafia-direitos-autorais. Acesso em: 10 jun. 2019. 
PALACE, Victor M. What if artificial intelligence wrote this? Artificial Intelligence and Copyright Law. Florida Law Review, Florida, v. 71, p. 217-242, 2018.

SALESFORCE. O que é inteligência artificial? Em 20 jan. 2017. Disponível em: https://www. salesforce.com/br/blog/2016/10/o-que-e-inteligencia-artificial.html. Acesso em: 10 jun. 2019.

SALESFORCE. Machine Learning e Deep Learning: aprenda as diferenças. 30 abr. 2018. Disponível em: https://www.salesforce.com/br/blog/2018/4/Machine-Learning-e-Deep-Learningaprenda-as-diferencas.html. Acesso em: 10 jun. 2019.

SCHÜSSLER, Paulo Junior; BASTIANI, Ederson; BUSSLER, NairanaRadtkeCaneppele. Inteligência Artificial e Aprendizado de Máquina: Utilizando o Entendimento da Inteligência Humana para Reprodução na Computação. In: SEMINÁRIO DE INICIAÇÃO CIENTÍFICA. SALÃO DO CONHECIMENTO UNIJUÍ, 26 Ijuí. Anais [...], Ijuí, 2018. Disponível em: https://publicacoeseventos. unijui.edu.br/index.php/salaoconhecimento/article/view/9828. Acesso em: 10 jun. 2019.

SORJAMAA, Tuomas. I, Author - Authorship and Copyright in the Age of Artificial Intelligence. 2016. 73f. Tese (Mestrado em Economia e Administração de Negócios) Departamento de Contabilidade e Direito Comercial, Hanken School of Economics, Helsinki, 2016.

SOUZA, Cezar Junior de; JACOSKI, Claudio Alcides. Propriedade Intelectual para Criações de Inteligência Artificial. In: CONGRESSO SUL BRASILEIRO DE COMPUTAÇÃO, 9, Criciúma.

Anais [...], Criciúma: UNESC, 2018. p. Disponível em: http://periodicos.unesc.net/sulcomp/article/ download/4794/4384. Acesso em: 29 jun. 2019

U.S. COPYRIGHT OFFICE. Overview of the Copyright Office. Disponível em: https://www. copyright.gov/about/. Acesso em: 10 jun. 2019.

U.S. COPYRIGHT OFFICE. Conpendium of U.S. Copyright Office Practices. § 313.2. 3. ed. 2017.

ZILIO, Diego. Inteligência artificial e pensamento: redefinindo os parâmetros da questão primordial de Turing. Ciências \& Cognição, Rio de Janeiro, v. 14, n. 1, p. 208-218, mar. 2009.

\section{Sobre os Autores}

\section{Carla Frade de Paula Castro \\ E-mail: carlafpc@gmail.com \\ Especialista em Relações Internacionais pela Universidade de Brasília em 2020. \\ Endereço profissional: Campus Universitário Darcy Ribeiro, Edifício CDT, Brasília, DF. CEP: 70904-970.}

\section{Jonath de Andrade Oliveira}

E-mail: jonath.fis@gmail.com

Especialista em Docência Superior pela Unyleya em 2018.

Endereço profissional: Ministério da Ciência, Tecnologia, Inovações e Comunicações, Esplanada dos Ministérios, Bloco R, Brasília, DF. CEP: 70044-900. 


\section{Lucas Barbosa de Araújo}

E-mail: lucas.barbosa@correadaveiga.adv.br

Bacharel em Direito pela Universidade de Brasília em 2018.

Endereço profissional: Corrêa da Veiga Advogados, SHN, Quadra 1, Bloco F, Sala 404, Brasília, DF. CEP 70.701-060.

\section{Luciano Andrade Pinheiro}

E-mail: luciano.pinheiro@correadaveiga.adv.br

Bacharel em Direito pela Universidade Federal da Bahia em 1999.

Endereço profissional: Corrêa da Veiga Advogados, SHN, Quadra 1, Bloco F, Sala 404, Brasília, DF. CEP: 70.701-060. 